\title{
Sexualidade masculina e saúde do homem: proposta para uma discussão
}

\author{
A discussion about masculine \\ sexuality and men's health
}

Romeu Gomes 1

1 Coordenação de Pós-Graduação em Saúde da Criança e da Mulher do Instituto Fernandes Figueira, Fiocruz. Av. Rui Barbosa, 716 Flamengo, 22250-020, Rio de Janeiro RJ. romeu@iff.fiocruz.br

\begin{abstract}
The present study aims to discuss aspects of the masculine sexuality that, if not properly approached, they can commit the man's health. In terms of method, the essay is used, understanding such a modality as a critical exercise of search, of exploratory character, concerning a theme or meditation object. The discussion begins with the question: what is the reason of speaking of masculine sexuality and the man's health? Soon after, sexuality, manliness and crisis are put in debate. In that debate, the tensions that appear between traditional patterns of the masculine identity and the possibility of living new forms of being man are pointed out. In the third part of the study, it focus the prevention of the prostate cancer as space in that are reflected subjects related to the masculine sexuality. Social reflexes of the imaginary concerning the masculine sexual identity can do of the rectal touch, preventive measure of that cancer type, a situation, at least, constraining. In the conclusion, it is aimed for the need of promoting more studies with men of different social and professional of health to contribute to the practices of health.
\end{abstract}

Key words Masculine sexuality, Man's health, Essay
Resumo O presente estudo objetiva problematizar aspectos da sexualidade masculina que, se não devidamente abordados, poderão comprometer a saúde do homem. Em termos de método, emprega-se o desenho de ensaio, entendendo tal modalidade como um exercício crítico de procura, de caráter exploratório, acerca de um tema ou objeto de meditação. A discussão é iniciada por uma reflexão em torno da questão por que falar de sexualidade masculina e saúde do homem? Em seguida, sexualidade, masculinidade e crise são postas em debate. Nesse debate, destacam-se as tensões que surgem entre padrões tradicionais da identidade masculina e a possibilidade de se viver novas formas de ser homem. $\mathrm{Na}$ terceira parte do estudo, focaliza-se a prevenção do câncer de próstata como espaço em que se refletem questões relacionadas à sexualidade masculina. Reflexos do imaginário social acerca da identidade sexual masculina podem fazer do toque retal, medida preventiva desse tipo de câncer, uma situação, no mínimo, constrangedora. Na conclusão, aponta-se para a necessidade de se promover mais estudos com homens de diferentes estratos sociais e profissionais de saúde e, a partir daí, caminhar na produção de conhecimentos que possam instrumentalizar as práticas de saúde.

Palavras-chave Sexualidade masculina, Saúde do homem, Ensaio 


\section{Palavras iniciais}

Por que discutir, especificamente, sexualidade masculina e saúde do homem? Um argumento que, de uma certa forma, podemos utilizar para responder a pergunta pode se voltar para o posicionamento de que os sujeitos - homens e mulheres - necessitam ser vistos tanto singularmente quanto no âmbito das relações e no campo mais amplo de sua cultura. Nesse sentido, enfocar a singularidade do homem não nos leva, necessariamente, a perda da dimensão relacional que a expressão gênero indica.

Outro argumento para sustentarmos o nosso tema surge do alerta de que não podemos desconsiderar que os avanços na forma de conceber o que é ser feminino, conseguido pelo movimento feminista, demandou deslocamentos no campo dos papéis masculinos. Isso se explica pelo fato de a sexualidade se constituir por referência (Damatta, 1997), em outras palavras, sendo demarcadas por uma profunda reflexividade. Assim, seja por causa da desestabilização ou pela necessidade de se rever os papéis sexuais no cenário atual, a discussão sobre masculinidade já é um movimento que vem preenchendo diferentes espaços (Gomes, 1998).

Ainda voltando ao título de nossa discussão, outra expressão nele usada pode causar questionamentos. Trata-se de saúde do homem. Essa expressão, à primeira vista, pode vir de encontro a uma política que preconiza a superação do modelo de mulher e saúde para o de gếnero e saúde. A proposta de programas de saúde voltados para gênero busca sair de um enfoque do risco e do dano da saúde da mulher para o da saúde como satisfação das necessidades humanas (Rios, 1993). Nessa proposta também está presente a idéia de que, para se chegar a um programa de saúde, a mulher como sujeito de direitos deve ser fortalecida. Destacar os direitos das mulheres contraria a dimensão relacional entre os gêneros? Necessariamente não porque para que se chegue à eqüidade deve-se, antes, combater as assimetrias. Fortalecendo um gênero em desvantagem poderia se promover uma melhor distribuição de poder entre os gêneros.

Nesse sentido, assim como a ênfase dos direitos das mulheres numa proposta de saúde com o enfoque de gênero é pertinente, uma proposta de se focalizar a saúde do homem também pode ser válida. É claro que essa proposta se sustenta a partir de outros propósitos, diferentes daqueles que visam fortalecer os direitos das mulheres. Não defendemos a pertinência da saúde do homem porque acreditamos que os homens estão perdendo seus direitos. Não estamos tratando de recaídas machistas.

Mas, antes de anunciarmos qual é o nosso propósito, gostaríamos ainda de fazer uma observação sobre gênero. O termo gênero passou a ser utilizado pelas feministas para traduzir as diversas formas de interação humana, buscando conceituar o gênero como forma de legitimar e construir as relações sociais. Sabemos que tanto o movimento feminista quanto a denominação de gênero cunhada por esse movimento tiveram e têm um importância fundamental para se pensar a relação entre homens e mulheres. Mas também sabemos que grande parte da produção dos estudos denominada de gênero ainda analisa suas questões em mão única. Alguns desses estudos reduzem a discussão ao campo do feminino (Gomes, 1998).

Nessas considerações iniciais, queremos sublinhar que o nosso propósito não é caminhar na direção oposta de se pensar a relação, privilegiando um gênero em detrimento de outro. Acreditamos que são igualmente válidos os posicionamentos que enfocam a saúde da mulher e a saúde do homem, desde que tais posicionamentos não percam a perspectiva relacional entre os gêneros e não se distanciem da promoção da saúde voltada para as necessidades humanas em geral. Pensar sobre a relação não significa desconsiderar demandas específicas de cada gênero.

A partir dessa perspectiva, objetivamos no presente estudo problematizar aspectos da sexualidade masculina que, se não devidamente abordados, poderão comprometer a saúde do homem.

Em termos de método de estudo, empregamos o desenho de ensaio, entendendo tal modalidade como um exercício crítico de procura, de caráter exploratório, acerca de um tema ou objeto de meditação, buscando uma nova forma de olhar $\mathrm{o}$ assunto (Tobar e Yalour, 2001).

Seguindo esse desenho metodológico, pretendemos inicialmente trazer algumas conclusões de estudos no campo das ciências sociais sobre a crise da masculinidade e a sexualidade do homem em geral. Em seguida, tentaremos estabelecer implicações desses aspectos no campo da saúde pública. Por último, em nossas considerações finais, formularemos questões para que novas discussões sejam promovidas no sentido de buscarmos abordagens adequadas para a promoção da saúde do homem. 


\section{Sexualidade, masculinidade e crise}

Afinal o que é ser homem? Segundo Nolasco (1997), tomando como base uma sociedade patriarcal, uma resposta para essa indagação poderia convergir para a representação do homem de verdade. Meninos e meninas crescem sob a crença de que mulher e homem são o que são por natureza. No modelo de masculinidade a ser seguido, ressaltam-se as idéias de que o homem de verdade é solitário e reservado no que se refere às suas experiências pessoais, ou, quando muito superficial e prático, direcionado para agir e realizar atividades. Por outro lado, espera-se que o homem compreenda demandas emocionais de suas parceiras e de seus filhos, sendo cúmplice e sensível.

Giddens (1993) observa que a sexualidade masculina tende a expressar mais inquietação do que a feminina porque os homens separam a sua atividade sexual das outras atividades da vida, onde são capazes de encontrar um direcionamento estável e integral. Essas inquietações cada vez mais vêm deixando de ser encobertas.

No final do século 20, ainda eram percebidas tensões na construção da identidade sexual masculina. Estudos realizados com homens das camadas médias urbanas e intelectualizados (Goldenberg, 1991) apontam para tensões masculinas diante de padrões tradicionalmente construídos. Os homens estudados expressaram a existência de alguns marcos vigentes para a afirmação da identidade masculina: $a$ iniciação sexual com prostitutas; a negação do homossexualismo; a referência constante a um certo padrão de comportamento sexual masculino (mesmo quando para rejeitá-lo); o desejo de corresponder às expectativas sociais (em especial dos amigos e das mulheres). Esses homens expressavam medo de serem questionados na sua masculinidade por se afastarem dos padrões tradicionais, por eles rejeitados.

Embora sabendo que há diferenças do que é ser homem e ser mulher no tempo, no espaço e, em específico, no interior das classes sociais (Jablonski, 1995), com base em Nolasco (1995), podemos observar que ainda há homens que utilizam padrões tradicionais - poder, agressividade, iniciativa e sexualidade incontrolada para construir a sua identidade sexual.

As tensões que surgem entre a manutenção do poder do macho nas relações íntimas entre os gêneros e a possibilidade de se viver novos modelos de masculinidade, em que se contemplam a associação entre sexo e afetividade e um relacionamento igualitário com a parceira amorosa, têm sido um dos motivos para se falar de uma crise masculina.

Ramos (2000) observa que, na década de 1980 nos EUA e nos últimos anos da década de 1990 no Brasil, surgiu uma discussão acerca da crise da masculinidade. Mas que crise é essa? Segundo o autor, com base em Trevisan, o masculino não está em crise, uma vez que ele, em si, é um gênero que vive em estado de crise permanente e endêmica na sociedade patriarcal. Nesse sentido, a masculinidade não é algo dado, mas algo que constantemente se procura conquistar. Para o autor, as conquistas do feminismo não determinaram a crise, mas a tornaram mais visível.

Seguindo a sua discussão, Ramos (2000) considera, baseado em Foucault, que falar atualmente de um novo homem e de uma nova mulher significa ordenar o que parece confuso. Quando não se pode mais falar de um único modelo hegemônico de ser homem e de ser mulher, do qual uma simples classificação binária (masculino versus feminino) dava conta, essa parece ser uma boa "técnica" para "restaurar" a classificação de gênero, mesmo que às avessas.

Damatta (1997) não aborda especificamente a crise da masculinidade, mas nos fala das inseguranças do ser homem. Para ele, num cenário em que se prega que a sexualidade se efetiva pela atração pelos opostos, a construção da masculinidade é atravessada por pontos de insegurança traduzidos principalmente pelo medo do homossexualismo e da impotência. Assim, dentre outros aspectos, os comportamentos masculinos apontam para o fato de que para que uma pessoa pudesse ser um homem, deveria primeiro sentir-se ameaçada de virar mulher.

Junto a esses medos, o homem também pode concentrar a sua preocupação de, mesmo sendo equipado para funcionar como macho, falhar na hora $\mathrm{H}$. Nesse sentido, mais do que ter um pênis é saber se relacionar. Relacionar, para Damatta, consiste basicamente em descobrir que "ser homem" não é o mesmo que "sentir-se como homem”. Ser homem [é] receber de uma mulher o atestado ou a prova de que se [é] verdadeiramente "homem".

A crise da masculinidade, para Nolasco (1997), em parte está associada a valores sociais que transcendem a dimensão do indivíduo; caracteriza-se pela tentativa de homens se diferenciarem do padrão de masculinidade socialmente para eles estabelecido. Para o autor essa crise representa a quebra do cinismo a respeito 
da existência de um homem de verdade em torno do qual todo menino é socializado. Por seu intermédio, temos acesso a uma reflexão em face da inclusão de seus sonhos e sentimentos como um valor pertencente ao cotidiano masculino.

Para ele, frente a esse cenário, abrem-se possibilidades relacionadas à transformação da intimidade, terreno tenso e confuso para o homem devido ao fato de os homens comumente pouco conhecerem as dimensões do contato, da proximidade, da troca, da solidariedade e da cumplicidade.

Goldenberg (2000), de certa forma, questiona a existência da crise do macho: Talvez o machão esteja realmente em crise, mas é possivel que até ele consiga sobreviver, só que será obrigado a coexistir com outras formas de ser homem. O que não sobrevive mais é um modelo hegemônico de masculinidade com base na força, poder e virilidade, embora homens (e mulheres!) continuem alimentando esse ideal.

Assim, independentemente de existir ou não a crise da masculinidade, o fato é que, paralelamente aos resquícios dos padrões patriarcais para uns e a vigência desses padrões para outros, experimentamos atualmente a possibilidade de construirmos a sexualidade masculina a partir de outros referenciais. Há momentos em que conseguimos mais dar voz à nossa forma de ser e, em outras vezes, reproduzimos os modelos, ficando até mesmo na caricatura desses modelos (Gomes, 1998).

\section{Reflexos da discussão da sexualidade masculina na saúde do homem}

Aspectos relacionados à percepção ou não da crise da masculinidade, em específico, e aos sentidos atribuídos à sexualidade masculina, em geral, produzem reflexos no campo da saúde, revelando dificuldades, principalmente, no que se refere à promoção de medidas preventivas.

Poderíamos citar vários exemplos para problematizar a dificuldade de promovermos medidas preventivas que demandem a discussão da representação da sexualidade masculina. Entre eles, podemos focalizar a nossa atenção para a prevenção do câncer de próstata.

No Brasil, o câncer de próstata é, sabidamente, um grave problema de saúde pública. Segundo o Instituto Nacional de Câncer (INCA), as altas taxas de incidência e a mortalidade dessa neoplasia fazem com que o câncer de próstata seja o segundo mais comum entre a população masculina, sendo superado apenas pelo câncer de pele não-melanoma. A estimativa do INCA, para 2002, é de que haja 25.600 novos casos desse câncer. As 7.223 mortes ocorridas em 1999 fizeram desse tipo de câncer o quarto tipo mais mortal, nesse período (www. inca.gov.br).

Ainda segundo o INCA, a detecção precoce do câncer de próstata é de fundamental importância para que se aumentem as possibilidades de cura. Entre as medidas preventivas, ressaltase o toque retal realizado por profissionais de medicina.

O toque retal é, relativamente, uma medida preventiva de baixo custo. No entanto, é um procedimento que mexe com o imaginário masculino, a ponto de afastar inúmeros homens da prevenção do câncer de próstata. Essa recusa não ocorre, necessariamente, por conta da falta de informações acerca da efetividade dessa medida preventiva. Quando arrebatados pelo senso comum, homens bem informados, no mínimo, resistem a se prevenirem dessa forma.

Não precisamos raciocinar muito para descobrirmos que o toque retal mexe com características identitárias masculinas. Damatta (1997) observa que a parte da frente do homem o diferencia da mulher, enquanto a sua traseira a ela o iguala. Assim, se o falo é a marca registrada do ser masculino, a nádega representa o outro lado da medalha.

Fazer o toque retal é uma prática que pode suscitar no homem o medo de ser tocado na sua parte "inferior". Esse medo pode se desdobrar em inúmeros outros. O medo da dor, tanto física como simbólica, pode estar presente no imaginário masculino. O toque, que envolve penetração, pode ser lido como violação e isso quase sempre se associa à dor. Mesmo que o homem não sinta a dor, no mínimo, experimenta o desconforto físico e psicológico de estar sendo tocado, numa parte interdita.

Ter ereção frente ao toque é outro medo. Ter ereção, que é uma possibilidade, pode fazer com que o homem pense que quem toca pode interpretar o fato como indicador de prazer. Em seu imaginário, a ereção pode estar associada tão fortemente ao prazer que não se consegue imaginá-la apenas como uma reação fisiológica.

Ficar descontraído, a pedido de quem faz o toque, para que o processo seja menos evasivo também pode trazer receios. O homem pode pensar que a sua descontração pode ser interpretada como sinal de que o toque nessa parte é algo comum e/ou prazeroso. 
Sabemos que esses medos, dentre outros, podem aflorar no imaginário dos homens imersos no senso comum. Mesmo para aqueles homens que conseguem imprimir uma racionalidade frente ao toque retal, não podemos descartar a possibilidade de a situação trazer constrangimentos que não são conscientes para esses homens.

Para o profissional de medicina, investido numa racionalidade que a clínica demanda, não cabe a possibilidade de que o toque tenha essas interpretações. Mas não podemos desconsiderar que tal profissional também sofra influências de aspectos que circulam no imaginário social ligados a questões da sexualidade masculina. Também não podemos descartar a possibilidade desse profissional ter um certo constrangimento em prever a existência dos medos que podem ser suscitados pelo seu toque ou não saber lidar com as possíveis fantasias que podem ser provocadas pelo procedimento.

Nesse sentido, mesmo tendo consciência dos possíveis problemas, nem sempre, os profissionais de saúde que se voltam para a prevenção do câncer de próstata estão devidamente preparados para lidar com os aspectos simbólicos envolvidos nessa prevenção. Podemos dizer isso não só para aqueles que realizam o toque retal, mas também para aqueles que planejam as campanhas de prevenção.

Assim, no campo da saúde pública é de fundamental importância que sejam promovi- das discussões voltadas para os sentidos atribuídos à sexualidade masculina para que não só a prevenção do câncer de próstata como outras ações tangenciadas por tais sentidos atribuídos possam ser melhor abordadas.

\section{Considerações finais}

Neste ensaio apenas pontuamos possíveis questões ligadas à saúde do homem que, para serem devidamente abordadas, devem ser examinadas à luz de referências da sexualidade feminina que integram o imaginário social. No entanto, a discussão precisa ser mais amadurecida. Falta-nos ainda desvendar mais esse imaginário, tentando compreender os conteúdos e a construção dos discursos que fala de tais questões.

Se desejarmos caminhar no enfrentamento de impasses que configuram a partir da dimensão simbólica, torna-se necessário que descubramos as imagens e os significados atribuídos pelos sujeitos, a partir de permanências culturais que se estruturam em torno da sexualidade masculina.

Para isso, estudos com homens de diferentes estratos sociais e profissionais de saúde precisam ser desenvolvidos para que possamos ancorar o debate num campo empírico e, a partir daí, caminharmos na produção de conhecimentos que possam instrumentalizar as práticas de saúde.

Assim, a discussão apenas começou.

\section{Referências bibliográficas}

Damatta R 1997. Tem pente aí?, pp. 31-49 In D Caldas (org.). Homens. Editora Senac, São Paulo.

Giddens A 1993. A transformação da intimidade: sexualidade, amor e erotismo nas sociedades modernas. Unesp, São Paulo.

Goldenberg M 1991. Ser homem, ser mulher: dentro e fora do casamento. Estudos antropológicos. Editora Revan, Rio de Janeiro.

Goldenberg M 2000. O macho em crise: um tema em debate dentro e fora da academia, pp. 13-39. In M Goldenberg (org.). Os novos desejos: das academias de musculação às agências de encontros. Editora Record, Rio de Janeiro.

Gomes R 1998. As questões de gênero e o exercício da paternidade, pp. 175-182. In P Silveira (org.). Exercício da paternidade. Editora Artes Médicas, Porto Alegre.

Jablonski B 1995. A difícil extinção do boçalossauro. In S Nolasco (org.) A desconstrução do masculino. Editora Rocco, Rio de Janeiro.
Nolasco S 1995. O mito da masculinidade. Editora Rocco, Rio de Janeiro.

Nolasco S 1997. Um "homem de verdade", pp. 13-29. In D Caldas (org.). Homens. Editora Senac, São Paulo.

Ramos MS 2000. Um olhar sobe o masculino: reflexões sobre os papéis e representações sociais do homem na atualidade, pp. 41-59. In M Goldenberg (org.). Os novos desejos: das academias de musculação às agências de encontros. Editora Record, Rio de Janeiro.

Rios R 1993. Genero, salud y desarrollo: un enfoque en construcción, pp. 3-18. In EG Gomez (org.). Genero, mujer y salud en las Américas. OPS/OMS, Washington (Publicação Científica, 541).

Tobar F \& Yalour MR 2002. Como fazer teses em saúde pública: conselhos e idéias para formular projetos e redigir teses e informes de pesquisas. Fiocruz, Rio de Janeiro. 